\title{
A Public Health Perspective on Consumer Product Design
}

\section{James Seifert*}

General Corporate and Business Mergers and Acquisitions, 775 Prairie Center Drive, Suite 400 Eden Prairie, MN 55344, USA

\begin{abstract}
Consideration of a public health perspective in consumer product design is a necessary enhancement to good product design, not just standard engineering practice. This study aims to determine a causal relationship between product design and level of injuries and related costs through the construction of a model that takes into account public health impacts of a particular design, both before product introduction and throughout the product life cycle. The model examines the relationship between design and injury rates by scoring injury data, which allows for interpretation as to design-related cause and potential removal of that cause through design change to eliminate a particular injury scenario.
\end{abstract}

Keywords: Public health perspective; Consumer product design

\section{INTRODUCTION}

The purpose of this paper is to begin the construction of a model for consumer product design that takes into account the public health impacts of a particular design, both before the product introduction and throughout the product lifecycle. Public health is concerned with identifying and measuring the total impact of an exposure on a population, regardless of how that exposure was created, imposed or encountered. Consumer product design has almost a singular focus on intended functionality for a seemingly infinite variety of purposes from lessening manual labor to skin treatments, all bound by the strict requirement of sustainable profitability. Within the scope of intended functionality, normally there is consideration given to the risk of physical injury that is taken into account through affordable design features and written warnings. However, outside the scope of intended functionality, there remains an additional and perhaps greater risk of physical injury and it is here that the tools and perspective of public health take into account the total risk of exposure to the population of foreseeable users.

By revealing and understanding the total risk to a population from a particular product design, public health can influence and improve product design. Ideally, the analytical tools of public health such as injury rates per use by injury category (fractures, choking) can be used to build a risk-adjusted model for risk of physical injury involving consumer products. This model can then be used to guide the design life of a consumer product. Moreover, it may also be the case that such public health analysis would argue against the introduction of a product in the first instance due to the high probability of physical injury from the exposure of foreseeable use.

\section{LITERATURE REVIEW}

Public health and the promise of reducing severe injury risk in the use of consumer products

The raw beauty of public health is the truth that large data reveals in connection with human health as a function of exposures from pathogens to foods to lifestyles to products. These truths provide a reliable and detailed blueprint for avoidance of the exposure and the reduction of risk. Starting with John Snow's remarkable achievement and perseverance in discovering the source of cholera at a public well in London in the 1850s, public health has been the source of definitive proof supporting the identification of population health risks.

In the course of discovering and refining data collection and analytical tools, public health has elevated the rational approach to health risks, their source, and implicitly how to reduce those risks. In practical as well as philosophical terms, reliable data is the source of truth. It is real and generally cannot be argued with as to whether something happened or not.

In unique ways, public health takes these individual bits of truth and amalgamates them into patterns that often reveal a cause or source. This is not a simple task. Within the scope of a meaningful population, what causes an individual's health condition may relate to more than one contributory source. It may be a hundred sources. Air, water and soil are vehicles for complex pathogens that,

Correspondence to: James Seifert, General Corporate and Business Mergers and Acquisitions, 775 Prairie Center Drive, Suite 400 Eden Prairie, MN 55344, USA, Tel: 6127707999; E-mail: jamesjseifert@gmail.com

Received: October 28, 2019, Accepted: January 17, 2020, Published: January 24, 2020

Citation: Seifert J (2020) A Public Health Perspective on Consumer Product Design. J Appl Mech Eng. 9:322. doi: 10.35248/2168-9873.20.9.322

Copyright: (C) 2020 Seifert J. This is an open access article distributed under the term of the Creative Commons Attribution License, which permits unrestricted use, distribution, and reproduction in any medium, provided the original author and source are credited. 
individually or collectively, lead to disease. Yet, the community of public health continues in its hunt for more refined tools and analysis to uncover causes of disease, simple and complex, especially at the earliest manifestation of a disease through a remarkably effective system of global surveillance organizations.

But the discipline of public health analysis and its tools, combined with its focus on surveillance, have never been applied to consumer product design in any broad or systematic way, particularly at the initial product design or concept stage. There is broad agreement within engineering about the basic safety design hierarchy aimed at lowering product usage risk: design, guard, warn. But the level of data gathering and data analysis needed to identify, precisely and quantitatively, what level of risk is presented by a particular product design in light of actual usage, has never been established within the consumer product engineering world. There is simply no consensus around where to draw the line in terms of quantifying a usage risk (an exposure) and deciding whether that risk should or can be eliminated by a design feature or whether the risk should be dealt with through the highly undesirable strategy of warning against the risk [1].

\section{Consumer product design and public health consequences}

The number of annual injuries and deaths related to the use of consumer products is large. From October 1, 2014-September 30, 2015 , the last year of aggregated data, consumer products were associated with 4000 deaths and 39.2 million medically treated injuries [2,3]. This compares with 37,133 deaths and 3.6 million injuries related to automobiles in 2017 [4]. According to at least one estimate and using a detailed methodology endorsed by the Consumer Product Safety Commission, the annual cost of all consumer product injuries in the United States is $\$ 1.0$ trillion dollars [5]. This is both a large human tragedy and an economic problem that, through any objective lens, is also a public health problem because it is directly correlated with consumer product use.

The central question for this paper then is what is the causal relationship, if any, between product design and this level of injuries and related costs? My working thesis is that the answer lies deep in the data that is available, directly from public reporting mechanisms or privately in testing and engineering reports. More practically to the value of any relationship between design and injury rates, what does the injury data reveal as to the cause and potential removal of that cause through design change in eliminating a particular injury scenario (an exposure) and thereby a category of injury?

A statistical laboratory for understanding the relationship between product design and injury rates is examining automobile death rates per 100,000 people in the U.S over the past 50 years. In January 1968 , the first federal safety standards for cars became effective. For cars manufactured after that date, shoulder belts for left and right frontseat vehicle occupants, side marker lights and collapsible steering columns were required [6]. These were significant initial design changes as they required major engineering efforts and increased unit costs. From then on there has been a regular and ongoing series of government mandated automobile design changes ranging from brakes to crashworthiness to airbags to traction control, all mandated by the government and all requiring major design and engineering efforts. Much of what we take for granted today in automobile safety was met with initial and vociferous resistance by the auto industry generally [7]. Nevertheless, the core rationale behind all of these mandated changes arose from accident data, reconstruction analysis, component failure analysis and design choices in terms of shape, material selection, information systems, sensors and the intersection of these choices and driver capabilities.

What was the effect of all these mandated changes? Total incidents, total injuries and injury rates per 100,000 people in the U.S. have all gone down since the era of auto safety began [8]. There is no reasonable explanation for the increase in auto safety and decrease in auto-related injuries other than the advent of better product design [9]. Further, one can see clearly that the ongoing research in auto safety consists in the finite analysis of the data revealed by the incidents themselves [10].

Public health and superior consumer product design have similar goals, but they are not identical: examining the standard of engineering care in product design and the lack of systematic enduser data collection

Public health is variously defined as promoting the health of populations through infectious disease detection and prevention, research surrounding outbreaks, food surveillance and most broadly by the Minnesota Department of Health as " focusing on the greatest health impact for the greatest number of people" [11]. These efforts are principally done through the accurate collection of epidemiological data. That is, data which identifies an exposure and a potentially related disease, condition or death and then tries to determine first a correlation between the disease and the exposure and then a potential causation.

The engineering perspective on safety and the importance of engineering decisions are likewise idealistic. According to the National Society of Professional Engineers Code of Ethics, the first fundamental cannon is: "Engineers, in the fulfillment of their professional duties, shall: (1) Hold paramount the safety, health and welfare of the public...." [12]. This broad mandate to "hold paramount" the safety of the public sets the priority for design choices, but it is not equivalent to the engineer's general legal duty which is to use "reasonable care" in the discharge of his or her duties. This reasonable care standard is further defined as: "that degree of skill and learning commonly applied under all the circumstances by the average prudent [engineer]..." [13]. This is a basic negligence standard. There is a critical distinction to be noted here. The key legal professional duty definition diverges relative to the first ethical cannon.

The law requires a standard of care which is common in the profession. It is not, however, a requirement to use the available technology to create the safest product [13]. This is seemingly at odds with the engineer's ethical cannon to put the public's safety in a paramount position.

The main problem with the negligence formulation of the engineer's professional duty legal standard is that logically, an entire segment of engineering could be substandard, yet an engineer practicing in this area could meet the professional standard of competence because it is the standard "common" within that segment of engineering. Hence, this is the fundamental reason why the legal system has the additional construct of "strict liability" because, even if an engineer designs a product within the standards of "learning commonly applied...", the product produced according to that standard may nevertheless be defective because it is "unreasonably dangerous" [13]. It is the legal system then, that is the fundamental 
driver of certain design choices, and not the engineer's professional code as it has been either applied or interpreted.

This is fundamentally why the public health perspective in consumer product design is a necessary enhancement to what should be considered good product design, not just standard engineering practice. The main problem with standard engineering practice as defined by what is common is that it allows for stagnation in the systematic collection, interpretation and application of product usage data from the field as would be inherent in a public health function. Consequently, the safety enhancements and lower risk profile that would naturally flow from assembling and systematically interpreting product usage data is missed and higher injury rates are the natural result.

There is little doubt that enhanced product liability exposure from incomplete data or inconsistent collection of injury data or the untimely interpretation and analysis of data is part of the problem. It explains why many manufacturers generally don't collect detailed usage and injury data. Even if the collection of data were done in a timely and accurate way, there is perhaps the lack of a corporate will to implement the design changes suggested by the data and why so many, I would suggest most, manufacturers simply don't bother at all with these processes.

However, for those manufacturers that takes the long view of a product lifecycle, navigating the legal risks associated with usage data collection, interpretation and then acting in a timely way on that data, it is highly beneficial. Such a fusion of data collection, interpretation and product design results in lower injury rates, lower warranty costs, higher customer satisfaction, increasing quality, and ultimately, enhances the overall brand of the manufacturer [14]. This is so because the field data inevitably reveals better, lower risk design options, at least initially, that can then be implemented in a timely way. Corporate leadership is the key to implementing such an approach [14].

\section{A new model: Connecting public health and consumer product design}

Starting with the perspective that end-user data reveals the truth about product life-cycle risk, a practical public health perspective in consumer product design seeks several types of often available data: injury type (and severity) by age and gender, injury scenario and specific product identification (and thereby identifying the product design introduced into the market) and the number of injuries per number of unique design units in the field. A mathematical framework can be constructed using this data that should be tracked over time.

The first step understands the injury severity levels, frequency rate and related index score. The generally accepted injury severity framework of the Abbreviated Injury Score (AIS) as described below is the standard for classifying injury severity. Its purpose is to correlate injury severity and morbidity and mortality. It is highly relevant in a clinical and health research setting (Table 1).

The AIS Scale and example injuries:

1. Minor-superficial cut

2. Moderate-fractured rib

3. Serious-compound fracture of the ulna
Table 1: Product A composite risk by user group by injury severity.

\begin{tabular}{cccc}
\hline $\begin{array}{c}\text { User } \\
\text { Group }\end{array}$ & $\begin{array}{c}\text { Injuries per 10,000 } \\
\text { products per year }\end{array}$ & $\begin{array}{c}\text { Injury } \\
\text { Severity } \\
\log 10\end{array}$ & $\begin{array}{c}\text { Author Composite } \\
\text { Risk Score Per 10,000 } \\
\text { products }\end{array}$ \\
\hline 1 & 20 & $\log 10^{1}$ & 200 \\
\hline 2 & 2 & $\log 10^{2}$ & 200 \\
\hline 3 & 4 & $\log 10^{4}$ & 40,000 \\
\hline 4 & 10 & $\log 10^{3}$ & 10,000 \\
\hline 5 & 4 & $\log 10^{3}$ & 4000 \\
\hline 6 & 1 & $\log 10^{5}$ & 100,000 \\
\hline 7 & 25 & $\log 10^{3}$ & 25,000 \\
\hline
\end{tabular}

4. Severe- perforated trachea

5. Critical-liver laceration combined with tissue loss

6. Maximum-100\% severance of aorta [15]

However, my purpose is to measure the risk of a product design as a function of severity and frequency. This requires the incorporation of the AIS categories into a risk formula that generates meaningful numerical distinctions between severity categories. Ideally, these distinctions should point to a problematic design. If a risk score fails to identify a risk that must be examined, for example, a single product involved death, and then it fails to properly guide the designer and has a diminished usefulness.

I propose an injury severity scoring system with an assigned Log10 value that incorporates the AIS categories in a way that is practical. It can be applied by organizations that may not have trained staff or access to data which would allow full usage of the AIS injury severity system. The injury severity categories I proposed and the related $\log 10$ values are as follows;

1. Log10 - Any injury requiring little or no medical attention for full recovery such as a pinch, slight bruise, contact with hot surface with slight or no pain. (AIS category 1)

2. Log $10^{2}$ - Any injury or condition requiring some nonemergency (immediate lifesaving) treatment such as a small laceration or deep bruise or muscle strain. (AIS category 2)

3. Log $10^{3}$ - Any injury or condition requiring emergency treatment that results in full recovery and no post-recovery limitations or major scarring. Significant pain and suffering involved such as broken bones. (AIS category 3 )

4. Log $10^{4}$ - Any severe injury of any kind that requires emergency medical care and results in permanent disability or major scarring such as amputation or loss of vision and has a significant risk of death associated it. Major pain and suffering involved. (AIS categories 4 and 5)

5. Log $10^{5}$ - Any injury that results in death either directly or indirectly. (AIS category 6)

By multiplying the log scale value by the number of injuries (within the severity category) per ten-thousand units (this number can be adjusted, it only needs to be consistent) and comparing that relative composite risk over time to a discrete product design, the specific risk of a product is revealed and can be evaluated.

In a straightforward manner, the two factors, rate and severity $\log 10$ value, focus the designer's choices by seeking to lower either the injury rate or the severity or both in order to lower the overall 
composite risk. The composite risk is useful as it can then be used to illuminate the cause of injuries in various scenarios by, for example, composite risk for rollover accidents of riding lawn mowers. Further, the composite risk can be constructed within age and gender categories to pinpoint what might be the design feature or human factor element that either individually or together led to a particular injury.

\section{A basic composite risk table may look like the following:}

Even with this simple table, if it is combined with the injury scenario and product identification, the value of such scoring is obvious. From the above we can see that risk within the user group 7 and user groups 3 and 4 spikes relative to the other categories and would this would lead a prudent engineer to further investigation. User group 6 involves a death and the scale correctly highlights this outcome for special focus. The importance of this type of data relative to potential design improvements and risk identification cannot be overstated. This data can be used to identify risk by, for example, age of product, component quality, injury scenario, geographic region, effect of new product design, environmental factors, human factors, and seasonality.

The design of the scale is aimed at highlighting injury trends that involve serious and chronic injury. Intentionally, this creates a major risk difference between the two lower level injury categories and those injuries that cause significant pain, permanent disability and death.

Critical to the validity of the composite risk value is the capture of all product involved injuries. This will include injuries where the product was properly or improperly used. Many well-meaning engineers will take issue with the inclusion of misuse-related injuries as defining the relative risk of a product. But this is the reality of a manufacturer's legal duty and thereby, should include the public health perspective. Even misuse, if it is foreseeable, requires the designer to make every reasonable effort-which includes features that increases the costs of a product-to anticipate the misuse in the form of better design [13].

The injury data gathering I suggest above is based on information that is often difficult to obtain in any public database. It is, however, information that is obtainable by the manufacturer. For example, the Insurance Institute for Highway Safety identifies risk in terms of automobile accidents per million vehicles, not per a particular model of car. But there are very reliable models such as those used by the CPSC that can be used to extrapolate to a composite risk rate per " $\mathrm{x}$ " thousand products for the particular manufacturer. The key is consistency in the injury rate and classifying the severity of the injury.

\section{A case study: Design modifications in consumer walk behind lawn mowers}

The history of the consumer rotary lawn mower provides a helpful example that demonstrates the value of critical design changes and the relationship with lower risk and fewer injuries. Tangentially, it raises interesting questions surrounding injury data gathering practices and when manufacturers had sufficiently certain knowledge of the efficacy of the specific design changes examined below which were eventually implemented. Couching the injury data collection issue in engineering practice and ethical terms, when was it common knowledge in this segment of engineering, that is, designing the consumer rotary lawnmower, that a bladebrake was standard engineering practice?

Consumer rotary lawn mowers were introduced to the consumer market during WWII because of the lack of steel needed for reel mowers. By 1957 the devastating injuries associated with lawn mowers were identified with certain data pointing to high injury rates among females and children [16].

By 1974, the Consumer Product Safety Commission (CPSC) estimated that power lawn mowers of all types were associated with 60,500 injuries per year that required emergency room medical treatment [17]. In 1973, the Outdoor Power Equipment Institute (OPEI), the main lawn mower trade association, began the formal process of proposing new safety standards for walk behind and ride on mowers, which began a very long proposal and hearing process [17]. The final Safety Standard for Walk behind Mowers was promulgated by the CPSC in 1979 and consisted of three parts, the mower must pass a foot-probe test, the blade must stop within three seconds after the operator lets go of the handle and a prominent safety label must attach to the machine. The scope and substance of the proposed safety standard was vigorously opposed by the OPEI, the industry representative [18]. Ultimately, the CPSC prevailed and its standard became effective June 30, 1982, nine years and 540,000 injuries after the standard was first proposed [19].

The positive public health consequences of the CPSC walk behind mower safety (design) standard are remarkably impressive. The most recent retrospective epidemiological study on lawn mower injuries in children show a 59\% decrease in emergency department cases involving children being injured by lawn mowers during the study period of 1990-2014 [20]. The National Electronic Injury Surveillance System (NEISS), the main CPSC database, indicates that ALL injury types involving walk behind lawn mowers that required emergency room treatment averaged 6291 people per year, down from the 70,000 injuries per year level in the 1970 s (Consumer Product Safety Commission, 2008-2017). This is stunning by any measure. Each year approximately 50,000 people, mostly children, avoid injury due solely to design changes in walk behind lawn mowers.

But why did it take so long? Further, might a public health perspective have impacted when the standard came into effect?

Even in 1957, White noted that walk behind mower injuries "... appear to follow definite patterns from the standpoint of anatomic location, type and severity" [21]. Not until 1982 did these patterns result in seemingly obvious design changes. The legal opinion in Southland is perhaps the best blueprint for why the industry was so slow to change. Cost and technical challenges were the main arguments, but these ring hollow in the face of the state of the art relative to the actual engineering challenges. The safety label was a simple addition. The mower deck and handle had to be extended and the blade stopping mechanism (operator presence controlOPC) required springs, a brake and cables. By 1982 the OPC/dead man switch was an engineering design option that had been used for over 100 years on trains, street cars, boats, forklifts, subways and construction equipment. Even given the harsh conditions that a mower must operate under, there is no record of industry research from when the pattern of injury was "definite" in 1957 until the CPSC safety standard was proposed in 1973. Although the OPC was a new device that required application engineering, particularly significant durability testing, the technical challenges were straightforward. 
Perhaps the answer to the question "Why did it take so long?" lies in perspective.

\section{The lowest risk exposure: Consumer surveillance using a health department model}

My fundamental argument is that designers and engineers of consumer products have a design obligation, co-equal to functionality and cost targets that requires the systematic collection and analysis of end-user injury data to the extent reasonably possible. Engineers and designers should have this public health duty because what they do has a major and nationwide (often global) public health impact. There is little difference between intentionally exposing a population to an infectious pathogen and selling a product that could have been reasonably designed better, resulting in lower end-user risk, by responding to end-user usage data. In both cases there is certainty someone's health will be negatively impacted. So too it is with the traditional activities of a Public Health Department, whether it is the surveillance of food supplies, hospitals, restaurants, vaccination programs, work environments or disease tracking, it is the general health of a discrete population that is understood and monitored at a detailed level. I suggest that designers of consumer products look to Public Health Departments as a model for how to scale a version of Public Health Department surveillance and apply it to consumer product risk analysis.

The bridge from public health to safer product design begins with better information gathering systems and a permanent data analytics function. End user injury data is the equivalent of exposure data. Near miss data (experienced risk with no injury) is also a potential source of highly valuable information, but it is much more difficult to systematically collect. Injury data represents a mechanism, pathway or vector by which a physical injury happened. This does not mean or imply that every injury or even hundreds of the same type of injuries would require a design modification- see hitting your thumb with a hammer. However, at least initially, injury data gathering and analysis uses a public health model and public health analytical tools, particularly the proposed. Composite risk score would reveal subtle as well as obvious risk areas for defined populations. This in turn would focus the designer on key risk areas that may potentially be eliminated. Some risks are inherent to the functionality of the product, like a hammer and thumb striking. But others, such as backing over a child with a riding lawn mower, would only be understood through systematic data collection and analysis.

The major benefit of systematic data collection and a permanent analytics function is the ability to react in a timely way. For some firms that may want to engage in the proposed risk identification, proper data gathering may pose a major challenge. Most of the injury data identified here is available through established manufacturing channels such as dealers, customer service, hotlines, distributors, the CPSC, reporting records, service records, marketing studies and target customer interviews. More anecdotal, but nevertheless relevant, data is available through competitor recall notices for directly competitive products or even similar products-various snow blower types, for example. Statistical validity as well as case validity would be critical for the analysis step and so the integrity of the data gathering process is essential to deriving reliable risk information.
Enhanced data gathering can be done by making it easy for the consumer to report injuries. Easily accessed product-attached phone numbers, websites and addresses are a start. Social media allows for immediate feedback and may be the most attractive platform for incident surveillance. It is critical for a responsible manufacturer to support and encourage a culture of reporting to create the ecosystem with the end user that motivates the user to report product "issues" for the purpose of making the product better.

What is being proposed may draw resistance and even ire from management and the legal department. It is acknowledged that there are confidentiality and system problems that must be overcome. Yes, what is being proposed is a new process with implied and permanent overhead costs. However, as has been demonstrated by many firms who have followed the lead of the pioneer of this process, the long-term public health, business and human benefits are profound. Leadership and the corporate will are the necessary forces. It is long past the point of debating the merits of such an approach to risk assessment and the implicit public health duty that risk information suggests [22]. First, it must be gathered to be understood and then it must be acted upon.

\section{A public and private data collection policy recommendation}

If the constructs laid out in this paper have merit, there are currently significant barriers prohibiting further consumer product risk research and ultimately implementing these constructs into practice. By way of example only, under the NEISS system, neither the manufacturer of the product nor the product serial number is part of the database. Without this information, it would be very difficult to assign injury rates, or injury severity rates, to a particular product model or design. The product manufacturer and serial number are like the DNA of an infectious pathogen. There simply is no substitute for knowing the specific product and thereby deriving the injury rate and severity for a specific design. A simple follow-up from the CPSC or the managers of the NEISS System to the injured person would seem to be a low expense and high-value process. Otherwise, there is no basis to tie the specific injury type to a specific product design.

I am keenly aware of the policy pushback that would be exerted by manufacturers by even suggesting the collection of such data. The resistance is likely based on a perceived enhanced product liability litigation risk and perhaps even the risk of punitive damages. However, any legislation that would require the CPSC to gather injury data that would include the manufacturer, model and serial number of the product, could include a confidentiality requirement whereby such information would only be disclosed to the manufacturer itself and could not be used in litigation.

This should make no difference to the attorney representing the injured party because such information would likely be discoverable independently through requests to the manufacturer for their independently gathered information.

\section{DISCUSSION AND CONCLUSION}

The NEISS system is a powerful tool for understanding the full nation-wide risk of a particular category of consumer product, for example, baby cribs. Because it only collects absolute numbers of 
injuries and types of injuries by gender and age, its overall affect is very limited regarding the understanding of specific products that should be redesigned because of the specific risks it suggests for a specific user group. Injury statistics generally are not dispersed evenly throughout the country so there may even be a variation by geographic regions that could be tied to language barriers, for example.

There is a wide variety of consumer product categories and a wide variety of different designs within specific categories of consumer products such as outdoor power equipment, shop tools, kitchen appliances, consumer chemicals and baby toys. The list is extensive and all product categories have a general risk profile, number of injuries per 100,000 people within the current NEISS system. But it is the specific risk profile, number and severity of injuries within a discreet user group by a specific product design that designers and engineers must understand in order to make their products materially safer.

Perhaps the best answer, for now, to narrow this massive data gap is for the CPSC to implement a voluntary data collection standard that would allow an analysis of specific risks by user group according to product design. It may be the case that many manufacturers simply need to be led and taught the value of such data collection. In the end, the benefits for both the manufacturer and the public are profound. Fewer injuries mean lower costs and risk for the manufacturer. More importantly, fewer injuries through better consumer product design lowers suffering and disability on a massive scale.

\section{REFERENCES}

1. Robinson LA, Viscusi KW, Zeckhauser R. Consumer warning labels aren't working. Harvard Business Review. 2016.

2. https://www.cpsc.gov/PageFiles/105435/cpsa.pdf.

3. United States Consumer Product Safety Commission. Annual Report to the President and Congress, 2017.

4. CDCNational Center for Health Statistics. Accidents or Unintentional Injuries, 2017.

5. Lawrence BA, Miller TR, Waehrer GM, Cohen MA, Zamula WW. The Consumer Product Safety Commission's Revised Injury Cost Model (Rep.). 2018.
6. https://www.govinfo.gov/app/details/CFR-2014-title49-vol6/CFR2014-title49-vol6-part571.

7. Nader R. Unsafe at any speed: the designed-in dangers of the American automobile. American Journal of Public Health. 2011;101:254-256.

8. Insurance Institute for highway safety. Fatality Facts 2017 State By State. 2018.

9. Insurance Institute for Highway Safety. Improved vehicle designs bring down death rates. Status Report, 50. 2015.

10. United States Department of Transportation (n.d). NHTSA Studies Vehicle Safety and Driving Behavior to Reduce Vehicle Crashes.

11. Minnesota Department of Public Health (n.d.). Introduction: Public Health in Minnesota.

12. National Society of Professional Engineers (n.d). NSPE Code of Ethics for Engineers.

13. Nichols SP. A design engineer's view of liability in engineering practice: Negligence and other potential liabilities. International Journal of Engineering Education. 2005;21:384-390.

14. Rubenstein D. Safety First. 2004.

15. Baker SP, O'Neill B, Haddon JrW, Long WB. The Injury Severity Score: A Method for Describing Patients with Multiple Injuries and Evaluating Emergency Care. J Trauma. 1974;14:187-196.

16. White WL. The Menace of the Rotary Lawn Mower. The American Journal of Surgery. 1957;93: 674-675.

17. Consumer Product Safety Commission. CPSC Seeks Offerors to Develop Mandatory Power Mower Safety Standards. 1974.

18. Southland Mower Co, et al. Consumer Product Safety Commission, US Court of Appeals for the Fifth Circuit, 619, F.2d 499. 1980.

19. Safety Standard for Walk-Behind Power Lawn Mowers, 16 C.F.R. $\$ 1205.2012$.

20. Ren KS, Chounthirath T, Yang J, Friedenberg L, Smith GA. Children Treated for Lawn Mower-Related Injuries in US Emergency Departments, 1990-2014. The American Journal of Emergency Medicine. 2017;35:893-898.

21. White WL. The Menace of the Rotary Lawn Mower. The American Journal of Surgery. 1957;93:674-675.

22. Raines SS. Conflict management for managers: Resolving workplace, client, and policy disputes. John Wiley \& Sons, NY, USA. 2012. 